Journal of Scientific Perspectives

Volume 3, Issue 1, Year 2019, pp. 41-46

E - ISSN: 2587-3008

URL: http://ratingacademy.com.tr/ojs/index.php/jsp

DOI: $10.26900 /$ jsp.3.005

Research Article

\title{
DIGITALIZATION OF SOLAR ENERGY: A PERSPECTIVE
}

\author{
Nevin TAŞALTIN *, ** \\ *Maltepe University, Department of Electrical \& Electronics Eng., TURKEY, \\ E-mail: nevintasaltin@maltepe.edu.tr \\ **Maltepe University Environment \& Energy Technologies Research Center, TURKEY \\ ORCID ID: https://orcid.org/0000-0001-6788-1605
}

Received: 13 January 2019; Accepted: 30 January 2019

\begin{abstract}
The risky limits of fossil fuel reserves are increasing the importance of energy in sustainable development. High economic growth rates of developing countries increase their energy consumption. Energy policies, green energy and new technologies are emerging as priority issues in the energy market. Global energy consumption is expected to increase by $28 \%$ by 2040. The changing geographical and economic balances in energy reveal the necessity of producing long-term solutions to the changes in energy markets. Solar energy has begun a fundamental transformation from an old analogue system to a fully digital network. This paper have presented a perspective on digitalization of solar energy including the relationship and benefits of, blockchain, industry 4.0, artificial intelligence and big data.
\end{abstract} data.

Keywords: Digitalization, solar energy, blockchain, industry 4.0, artificial intelligence, big

\section{INTRODUCTION}

The risky limits of fossil fuel reserves are increasingly increasing the importance of energy in sustainable development. Global energy consumption is expected to increase by $28 \%$ by 2040. High economic growth rates of developing countries increase their energy consumption. The changing geographical and economic balances in energy reveal the necessity of producing long-term solutions to the changes in energy markets. Energy policies, green energy and new technologies are emerging as priority issues in the energy market. In the case of predictions, renewable energy will stand out as the fastest growing energy source in the world. Despite this increase in renewable energy sources, coal, oil and natural gas are expected to maintain their position as main energy sources by 2040 and $77 \%$ of global energy consumption will still be provided from fossil fuels in 2040. Natural gas among fossil fuels is expected to be the fastest growing energy type. $33 \%$ of global energy consumption comes from 
petroleum and liquid fuels in 2017 , while by 2040 this ratio is expected to decrease slightly to $31 \%[1-4]$.

It is foreseen that nuclear energy consumption worldwide will increase by 1.5 times in the period 2018- 2040. Nuclear energy is expected to be the second fastest growing energy source in the world with this projected increase. Increasing energy demand and energychanging balances are changing the supply and demand markets. For the importer of energy and the dependence on foreign countries in this area, getting rid of energy dependency is of great importance in terms of achieving economic independence. In addition, the geopolitical uncertainty environment, the approach to the limits of sustainability in the use of fossil fuels, and the climate change that has begun to give dramatic signals make it necessary for countries to recreate their energy cycles as soon as possible. When producing solutions for climate change, it is necessary to focus not only on increasing alternative energy sources, but also on reducing energy consumption and developing solutions for energy efficiency [1-4].

Intelligent technologies, including the connection of objects to the Internet, storage of big data, cloud computing systems, artificial intelligence (AI) development, virtual reality, and other forms of advanced communication, fundamentally change the operation of businesses and societies [5-7].

When Industry 4.0 is applied to photovoltaic systems, it provides the stability and reliability needed to manage energy production more effectively. With the digitalization of the solar sector, the increase in producibility will also make the industry more competitive. With the application of digital technologies, smart panel photovoltaic systems offer opportunities to obtain more energy from less solar panel. When the data from the panel are analyzed correctly, many data about panel usage and production are obtained. The use of algorithms allows the use of algorithms to make accurate predictions and make real-time decisions that increase energy production, so that the return on investment of each solar energy increases very rapidly [5-7].

Through the monitoring technology that technology companies continue to develop, it allows photovoltaic system owners and operators to remotely view and remotely perform all details of photovoltaic systems. Each panel provides individual data about the performance of the entire array, which, when combined, provides precise information about the performance of the entire system. Energy managers can scan many photovoltaic systems in real time from any point they connect to the internet using their personal computers or smartphones, and quickly identify the causes of faults and problems. The real-time monitoring technology allows maintenance in the photovoltaic system without a problem yet, eliminating the need for unplanned, tiring, onsite testing that is costly. As a result, plant owners, operating and maintenance operators can ensure that solar panel facilities always operate at maximum efficiency. Such solutions optimize plant uptime and improve energy efficiency. Investors face a much lower failure rate, thus increasing both the return on investment and the operating costs. There is no doubt that many new technologies will be used with the further development of technology or even more costs. A technology that will provide information about the period to be cleaned and the amount of water to be used by a machine to be used for the cleaning of the panels can give information about the data to be taken from the field with the data obtained from the field, which string (panel set) yield is reduced, short circuit or need to change. The sensor technology will allow the panels to see the sun at the right angle, allowing them to control the direction to get more efficiency from the sun [5-7].

Conventional electricity transmission systems are vulnerable to attacks from anywhere in the world due to their centrist nature, as they are exposed to losses due to the transmission of electricity to remote locations. The electrical systems we need for almost all of our needs are exposed to many attacks and malfunctions in the world and cause problems in societies. In 
2003, it occurred in the NorthEastern United States and Canada's also affecting power outages and Ireland, Ukraine, Switzerland, society occurring in countries such as Turkey cuts significantly influence are just a few of them [8-10].

Blockchain technology, in which we are familiar with crypto coins, has been proposed to be used in energy transmission systems as a solution to the negative aspects of the system instead of the traditional electricity transmission / distribution systems. While these losses are prevented in the non-centralized system against the losses encountered in transmission to long distances, it is foreseen that operation costs will decrease and personnel costs will decrease. Blockchain technology is a non-centralized system without a single authority, and basically all users in the system can access the data. Therefore, data encryption is used in the system [8-10].

It is thought that more efficient energy trade will be provided in the electricity transmission systems using Blockchain technology. With this system, consumer units will also be able to be included in the system as producers. Through this system, each unit can also monitor the energy produced in the other unit and the system becomes transparent. In the approach to solar energy, a house with a solar panel can be included in this market by selling more than the energy it produces to a non-centralized person (peer to peer). In this way, a local solar market can be established, income flow can be ensured and even a single panel can be included in this system [8-10]. The surplus energy produced by solar panels placed on the roofs of buildings can be sold to neighboring buildings. Although these buildings are connected to each other via the city network, they can use Blockchain systems for trading. These and many other Blockchain-based pilot projects can be implemented in all countries. This approach, which is prepared to be used in solar energy technology, allows us to keep track of the current amount of energy produced, cost, where the energy is produced, where this energy is needed. In public spaces, it can also be supported by communities producing electricity with solar panels. In this way, increase in orientation towards solar energy can be achieved and loss rates can be reduced and social contribution can be provided to energize critical areas and effective use can be increased [8-10].

In the near future, Artificial Intelligence (AI) will further automate solar industry operations and increase efficiency in the renewable energy sector. With the Big Data analytics, which is one of the leading disciplines in AI and its advancement in the digital world, sustainability parameters such as decision making and planning, status monitoring, maintenance, robotics, audits and supply chain optimization can be most effectively presented to the renewable energy world $[11,12]$. With the benefits of this relationship of AI and Big Data;

- The development of robotic applications, which are widely used for remote examination, accelerates day to day.

- The decision-making mechanism of monitoring/scanning robots using a range of technologies, such as microwave and ultrasonic transmitters / receivers, which can approach the surface of the Solar Energy panels to reveal the error and failure of the materials used in solar panels, can be improved by increasing the accuracy share day to day.

- Efficient and efficient inspection of solar energy panels of autonomous drones with real-time artificial intelligence-assisted analyzes can be achieved by maximizing the efficiency of minimum human power.

- Great data to benefit from historical data and artificial intelligence, which accelerates due diligence, optimizes the energy used for planning and analysis. 
- Enables the establishment of systems that can balance supply and demand with minimum margin of error in energy supply.

- Estimates such as forecasting in which months of the year the region will be cloudy and the estimation of the current system to produce effective / usable energy in a yearly average. With the assumption that production will be performed at full capacity with the exception of the low production forecast, the facilities producing energy in fossil fuels may reduce the use of fossil fuels or stop it for a short time. Thus, when different sources of renewable energy meet in the same database, fossil fuel consumption can be gradually reduced.

- Within the scope of the cause-effect relationship within these main features; In order to realize the problems in the electricity grid in advance, to reduce the network problems, and to use the AI in order to get the systems back up to speed, the research studies have started. AI will be realized in cooperation with AI and big data in order to eliminate power imbalances in electricity networks, to prevent failures and damages that may occur in the network and to be used as a help element in the faster elimination of blackouts, cyber attacks, solar burst and other reasons.

All of these relationships will feature the technology of Internet of Things, the shining star of the IT industry, to work healthy and create the Big Data infrastructure. Thus, the data of the solar energy panels rather than the interconnected system with the electrical connection in the networks will all be interconnected.

\section{RESULTS AND CONCLUSIONS}

The solar energy sector is considered as one of the most important investment in renewable energy resources invested together with government incentives. When the fees are taken into account, it appears to be reasonable investment as depreciation period. However, when it comes to sustainability costs and business needs in applications such as solar farms, an investment is difficult for the investor. Therefore, it is possible to minimize the sustainability costs by making use of the developing technology. With the concept of the Internet of Things (IoT), each solar system can be an object; NarrowBand IoT (NB-IoT) technology with low power consumption will allow you to observe all values such as battery, inverter, fault information, total generated energy by using the energy produced. In this way, the investor can share your monthly/weekly/yearly data with the energy you produce in the future, compare with the weather information and the energy you produce, and share this information with you if your panel needs to be cleaned. In order to facilitate our lives, the energy sector is of great importance in smart city applications prepared for use in all sectors such as transportation, energy and communication. The increasing number of electric cars and the number of devices we use each day makes the efficient use of solar energy more important. When energy distribution companies enter their data in forecasting systems, the energy needs of hours/minutes will be revealed and the systems that will be put into use in order to assist the city network will be widespread in the coming days. Solar energy technology will be transformed into sustainability, low cost and scalable systems for both countries and investors. 


\section{REFERENCES}

[1] https://assets.kpmg/content/dam/kpmg/tr/pdf/2018/02/sektorel-bakis-2018-enerji.pdf

[2] https://www.mmo.org.tr/sites/default/files/EnerjiGorunumu2018_1.pdf

[3]http://www.enerji.gov.tr/File/?path=ROOT\%2F1\%2FDocuments\%2FEnerji\%20ve\%20Tab ii\%20Kaynaklar\%20G\%C3\%B6r\%C3\%BCn\%C3\%BCm\%C3\%BC\%2FSayi_15.pdf

[4] http://www.yegm.gov.tr/document/enver_gelisim_rapor_2018.pdf

[5] STOCK, T, SELIGER, G. 2016. Opportunities of Sustainable Manufacturing in Industry 4.0. Procedia CIRP 40 536-541.

[6] KAGERMANN, H. 2014. Change Through Digitization-Value Creation in the Age of Industry 4.0. Management of Permanent Change 23-45.

[7] LISERRE, M, SAUTER, T, HUNG, J.Y. 2010. Future Energy Systems: Integrating Renewable Energy Sources into the Smart Power Grid Through Industrial Electronics. IEEE Industrial Electronics Magazine 4, 1, 18-37.

[8]ZHENG, Z, XIE, S, DAI, H.N., CHEN, X, WANG, H. 2018. Blockchain challenges and opportunities: a survey. Int. J. Web and Grid Services, 14, 4, 352-375.

[9] IMBAULT, F, SWIATEK, M, BEAUFORT, R, PLANA, R. 2017. The green blockchain: Managing decentralized energy production and consumption. IEEE Industrial and Commercial Power Systems Europe (EEEIC / I\&CPS Europe), 17029854.

[10] XU, C, WANG, K, GUO, M. 2017. Intelligent Resource Management in BlockchainBased Cloud Datacenters. IEEE Cloud Computing 4, 6, 50-59.

[11] ZHOU, K, FU, C, YANG, SHANLIN. 2016. Big data driven smart energy management: From big data to big insights. Renewable and Sustainable Energy Reviews 56, 215-225.

[12] KOLOKOTSA, D, ROVAS, D, KOSMATOPOULOS, E, KALAITZAKIS, K. 2011. A roadmap towards intelligent net zero- and positive-energy buildings. Solar Energy 85, 12, 3067-3084. 
TAŞALTIN / Digitalization of Solar Energy: A Perspective 